Journal of Mathematics and Informatics

Vol. 20, 2021, 61-72

ISSN: 2349-0632 (P), 2349-0640 (online)

Published 23 April 2021

www.researchmathsci.org

DOI: http://dx.doi.org/10.22457/jmi.v20a07190

Journal of

Mathematics and Informatics

\title{
Modeling and Optimization of Clean Water Distribution Networks
}

\author{
Lucas Edward $^{I^{*}}$, Mashaka James Mkandawile ${ }^{2}$ and Verdiana Grace Masanja ${ }^{1}$ \\ ${ }^{1}$ Department of Applied Mathematics and Computational Science \\ Nelson Mandela African Institution of Science and Technology \\ P.O. Box 447, Arusha, Tanzania. \\ ${ }^{2}$ College of Natural and Applied Sciences, University of Dar-es-salaam \\ P.O. Box 35065, Dar-es-salaam, Tanzania. \\ *Corresponding author. Email: edwardl@nm-aist.ac.tz
}

Received 3 March 2021; accepted 15 April 2021

\begin{abstract}
In this study, an optimal clean water distribution system cost model has been developed to find the minimum cost to distribute clean water. The model was then tested with real data collected from Ihumwa water distribution network of Dodoma city and other treatment cost data from literature to test the workability of the model. Hydraulic parameters such as head losses of the pipes, flow velocity and pipe pressure are calculated using water flow software. The resulted model was solved using LINGO software and the optimal cost of clean water distribution system was found by testing the different maximum and minimum velocity and pressure that give an optimal cost.
\end{abstract}

Keywords: Modeling, optimization model, clean water distribution

AMS Mathematics Subject Classification (2010): 46N10

\section{Introduction}

The first and most important public service that people demand is a consistent supply of clean and safe water. A network of pipes, tanks, pumps, valves and other hydraulic elements consists of the water distribution system. The goal is to supply quality water under specific pressure conditions and a range of specifications to customers.

The UN Water Development Report of 2018 shows that many people will be affected by drinking water shortages by 2050 . This is due to increased demand for water, reduced water resources and increasing water pollution driven by spectacular population and economic increase [1].

It is complex to manage and allocate water from the multi-reservoir systems and thus requires dynamic modeling systems to obtain optimal performance [2].

The water distribution network consists of pumps, pipes, valves and node sets of a reservoir and pipe connections. A set of stationary points, some of which are nonlinear, 
Lucas Edward, Mashaka James Mkandawile and Verdiana Grace Masanja

determines the flow pressure in the network. The experimentally determined relationship between the pressure and the flow rate is associated with nonlinear conditions (i.e. the discrete pressure from one point of the pipe to the other is a flow rate/time nonlinear function).

Based on [3], the problem of classical pipe network analysis is based on finding a set of flows and pressures in the water distribution pipe network when inputs and withdrawals are known. New water systems (NWAs) are difficult to manage due to increased urbanization, changing consumer needs, old infrastructure, operating costs and lack of water resources.

The study of [4] contends that in a wide range of industrial processes and urban centers, WDNs are present. WDNs are formed by reservoirs, pipes, nodes, loops and pumps and their design can be formulated as an optimization problem. The primary goal is to minimize the cost of distributing water, which depends on pipe diameters and flow directions, in the given network.

In the study of [5] used an integrated model of Multi-Criteria Decision Making (MCDM) and Integer Linear Programming (ILP) to optimize of water loss management strategies.

The study of [6], shows a design method for a fixed flow speed, where the entire cost corresponds to that expenses of the demand flow variable. The method is built on the Granados method, which is an instinctive and practical gradient based technique. To familiarize it to regular demand, the idea of similar flow speed and volume is presented and used in a simple case study.

Effective decision-making when it comes to water and wastewater services requires a comprehensive approach that ensures the best return at an acceptable level of risk, taking into account the costs of constructing, operating, maintaining and disposing of capital assets over their lifetime [7].

In the study of [8] the optimization model known as deterministic mathematical programming proposed to determine the minimum cost of looped WDNs. The model optimization taking into account pipe lengths and a discrete set of commercially available diameters and the constraints is mass balances in nodes, energy balances in loops and hydraulic equations. The discrete optimization problem is reformulated by generalized disjunctive programming to a non-linear integer-blended programming problem (MINLP). The problem is solved by General Algebraic Modeling System (GAMS) environment.

Moreover, to exercise the modeling and optimization of water distribution one needs to have the best model that will optimize the cost of clean water distribution networks in the selected area or data of a given area. In many literatures, the available models for optimization of water distribution network have been used to optimize the cost based on hydraulic parameters, example in the study of [9] which took place in the southern area of Italy (Crotone), it uses nonlinear optimization model to optimize drinking water distribution systems in relation to the effects of climate change. PSO 
Modeling and Optimization of Clean Water Distribution Networks

method was used in the study of optimization of tree Pipe networks layout and size, by [10]. [11] Used mixed integer Linear Programming (MLP) to optimize the allocation of water and the location of one more reservoirs.

Although many studies have been conducted on various cost optimizations for water distribution networks, some of these studies do not consider the cost of water treatment parameters and hydraulic parameters in the same model while formulating water cost optimization models.

The aim of this study is to formulate an optimization model to optimize the cost of clean water distribution network using [12] model for the hydraulic parameter used, i.e. pressure, velocity and flow rate and model by [13] for the case of water treatment parameters. With a slight modification of the parameters for these two models, a new model has been developed in this study to optimize the cost of a clean water distribution system.

\section{Optimization model}

The LP model is based on the papers of [12] and [13]. The objective function to be minimized is the price of clean water distribution networks cost, composed of pipes diameters cost and the associated water treatment parameter. The constraints are pressures and velocity limits, maintenance cost, energy cost, chemical for water treatment cost and personnel cost.

\subsection{Definition of the model parameters and variables}

Table 1 defines parameters and variables of the model:

Table 1: Description model parameters and variables

\begin{tabular}{cl}
\hline Symbols & \multicolumn{1}{c}{ Definition } \\
\hline $\mathrm{L}_{\mathrm{n}}$ & The length of pipe $\mathrm{n}$ \\
$\mathrm{CP}_{\mathrm{n}}$ & The cost of unit length of pipe $\mathrm{n}$ \\
$\mathrm{C}\left(\mathrm{d}_{\mathrm{n}}\right)$ & Represents the cost of the pipes \\
$\mathrm{d}_{\mathrm{n}}$ & Diameter of pipe $\mathrm{n}$ \\
$\mathrm{M}_{\mathrm{c}}$ & Maintenance costs \\
$\mathrm{E}_{\mathrm{c}}$ & Energy cost \\
$\mathrm{C}_{\mathrm{c}}$ & Chemical cost \\
$\mathrm{P}_{\mathrm{C}}$ & Personnel cost \\
$\beta$ & Maintenance cost coefficient \\
$\alpha$ & Energy cost coefficient \\
$\delta$ & Chemical cost coefficient \\
$\mu$ & Personnel cost coefficient \\
$\mathrm{Y} 1$ & Number of Maintenances \\
$\mathrm{Y} 2$ & Average quantity of energy
\end{tabular}


Lucas Edward, Mashaka James Mkandawile and Verdiana Grace Masanja

$\begin{array}{cl}\text { Y3 } & \text { Average quantity of chemicals } \\ \text { Y4 } & \text { Number of personnel. } \\ \mathrm{P}_{\mathrm{i}} & \text { Represent pressure head at node i } \\ \mathrm{P}_{\mathrm{j}} & \text { Represent reference node pressure } \\ \text { Prmax } & \text { Maximum pressure } \\ \mathrm{Prmin} & \text { Minimum pressure } \\ \mathrm{V}_{\min } & \text { Minimum velocity } \\ \mathrm{V}_{\max } & \text { Maximum velocity } \\ \mathrm{Q}_{\mathrm{n}} & \text { flow discharge } \\ \mathrm{APC} & \text { Average person cost } \\ \mathrm{ACT} & \text { Average chemical cost } \\ \mathrm{AQC} & \text { Average quantity of chemicals } \\ \mathrm{AQE} & \text { Average Quantity of energy in } \mathrm{KWh}\end{array}$

\subsection{Objective function.}

The sum of all tube diameters and their costs and the cost of treatment must be considered in the objective function.

$$
\operatorname{Min}\left(C(d n)+T\left(m_{c}+E_{c}+C_{c}+P_{c}\right)\right)
$$

where $C\left(d_{n}\right)$ represents the cost of the pipes which includes transportation and installation cost and $T\left(m_{c}, E_{c}, C_{c}, P_{c}\right)$ is the treatment cost which include maintenance cost, energy cost, chemical cost and personnel cost.

The cost of the pipes is given as in equation (2)

$$
C\left(d_{n}\right)=\sum_{n=1}^{N P} L_{n} C P_{n}\left(d_{n}\right)
$$

The treatment cost is given as in equation (3)

$$
T\left(m_{c}+E_{c}+C_{c}+P_{c}\right)=\beta Y_{1}+\alpha Y_{2}+\sigma Y_{3}+\mu Y_{4}
$$

Now the objective function which is the total cost of distributing clean water is given as equation (4)

$$
\operatorname{Min}\left(\sum_{n=1}^{N P} L_{n} C P_{n}\left(d_{n}\right)+\beta Y_{1}+\alpha Y_{2}+\delta Y_{3}+\mu Y_{4}\right.
$$

Maintenance cost coefficient ( $\beta$ ) is given as in equation (5)

$$
\beta=\frac{A M C}{N M}
$$

Energy cost coefficient $(\alpha)$ is given as in equation (6) 
Modeling and Optimization of Clean Water Distribution Networks

$$
\alpha=\frac{A E C}{A O F}
$$

Chemical cost coefficient $(\delta)$ is given as in equation (7)

$$
\delta=\frac{A C T}{A Q C}
$$

Personnel cost coefficient $(\mu)$ is given as in equation (8)

$$
\mu=\frac{A P C}{N P}
$$

The first term of the objective function has the non-linearity property therefore is multiplied by the summations and non-zero unit variables such as $\mathrm{X}_{\mathrm{N}}$. The addition of all commercially available pipes gives the general objective function as in equation (9).

$$
\operatorname{Min}\left(\sum_{j=1}^{N P A} \sum_{n=1}^{N P} L_{n} C P_{n}\left(d_{n}\right)+\beta Y_{1}+\alpha Y_{2}+\delta Y_{3}+\mu Y_{4}\right)
$$

where NPA is the number of tube sizes available on the marketplace.

\subsection{Constraints of the objective function}

The following constraints apply to the objective function:

\subsubsection{Pressure constraint}

The pressure constraint for this study is upper and lower pressure that gives the optimal cost for clean water distribution which is given by equation (10) and equation (11).

$$
\begin{aligned}
& P_{i} \geq P r_{\text {min }} \\
& P_{i} \leq P r_{\text {max }}
\end{aligned}
$$

where $P_{i}$ is the pressure head at node $\mathrm{i}$, which is given by equation (12)

$$
P_{i}=P_{j}+\Delta Z-H L_{j}
$$

where $H L_{j}$ are head-losses from reference node and end at node $\mathrm{i}$, which are calculated using Hazen-Williams formula for this study and they are given by equation (13) below.

$$
H L_{j}=\frac{10.67 * L_{n} * Q_{n}^{1.85}}{C^{1.85} * d_{n}^{4.87}}
$$

Equation (12) substituted into equation (10) and (11), respectively, to give equations (14) and (15).

$$
P_{j}+\Delta Z-H L_{j} \geq P r_{\min }
$$


Lucas Edward, Mashaka James Mkandawile and Verdiana Grace Masanja

$$
P_{j}+\Delta Z-H L_{j} \leq P r_{\max }
$$

The equations (14) and (15) are multiplied by summation and non-zero unit variable in the head loss to make them linear constraints as in equation (16) and (17)

$$
\begin{aligned}
& P_{j}+\Delta Z-\sum_{j=1}^{N P R} H L_{j} X_{N J} \geq P r_{\min } \\
& P_{j}=\Delta Z-\sum_{j=1}^{N P R} H L_{J} X_{N J} \leq P r_{\max }
\end{aligned}
$$

Therefore, equation (16) and (17) are the model pressure constraints. Where NPR is the number of pipes connected to the reference node.

\subsubsection{Velocity constraint}

The Flow velocity constraint is given as in equation (18).

$$
V_{\min } \leq V_{n} \leq V_{\max }
$$

$V_{\min }$ is the minimum allowable flow speed in the pipe, $V_{\max }$ is the maximum allowable flow speed in the pipe and $V_{n}$ is the pipe flow speed which is given by equation (19).

$$
V_{n}=\frac{4 Q_{n}}{\pi d_{n}^{2}}
$$

Substituting equation (19) in equation (18) and multiplying by summation and non-zero unit variable results in equation (20) which is a velocity model constraint.

$$
V_{\text {min }} \leq \sum_{j=1}^{N P A} \frac{4 Q_{n}}{\pi d_{n}^{2}} X_{N J} \leq V_{\text {max }}
$$

\subsubsection{Maintenance constraint}

The products of maintenance coefficient cost and the number of maintenance in a month is greater or equal to the average maintenance cost and it is given by equation (21).

$$
\beta Y_{1} \geq M
$$

\subsubsection{Energy constraint}

The product of energy coefficient cost and the average quantity of electricity used is greater or equal to the average cost of electricity and it is given by equation (22).

$$
\alpha Y_{2} \geq E
$$


Modeling and Optimization of Clean Water Distribution Networks

\subsubsection{Chemical constraint}

The product of chemical coefficient cost and the average quantity of chemical is greater or equal to the average cost in chemical and it is given by equation (23).

$$
\delta Y_{3} \geq Z
$$

\subsubsection{Personnel constraint}

The product of personnel coefficient cost and the number of personnel is greater or equal to average personnel cost and it is given by equation (24).

$$
\mu Y_{4} \geq P
$$

\subsection{Developed optimization model}

The optimization model developed in this study

Objective function

$$
\operatorname{Minimize}\left(\sum_{j=1}^{N P A} \sum_{n=1}^{N P} L_{n} C P_{n}\left(d_{n}\right)+\beta Y_{1}+\alpha Y_{2}+\delta Y_{3}+\mu Y_{4}\right.
$$

Subject to the constraints

$$
\begin{gathered}
P_{j}+\Delta Z-\sum_{j=1}^{N P R} H L_{j} X_{N j} \geq P r_{\text {min }} \\
P_{j}+\Delta Z-\sum_{j=1}^{N P R} H L_{J} X_{N j} \leq P r_{\max } \\
V_{\min } \leq \sum_{j=1}^{N P A} \frac{4 Q_{n}}{\pi d_{n}^{2}} X_{N j} \leq V_{\max } \\
\beta Y_{1} \geq M \\
\alpha Y_{2} \geq E \\
\delta Y_{3} \geq Z \\
\mu Y_{4} \geq P \\
Y_{1}, Y_{2}, Y_{3}, Y_{4} \geq 0 \\
X_{1}, X_{2}, X_{3}, X_{4}, X_{5} \geq 0
\end{gathered}
$$

\section{Model application}

The model developed in this study for analyzing the clean water distribution cost has been applied to the water treatment data for DUWASA (these are secondary data) and hydraulic data (raw data) collected from ongoing water projects in Dodoma city. 
Lucas Edward, Mashaka James Mkandawile and Verdiana Grace Masanja

Table 2: Details of the pipe laid, IHUMWA, DODOMA

\begin{tabular}{lllllc}
\hline Junction & pipe size & Length $(\mathrm{m})$ & Discharge $(1 / \mathrm{s})$ & Head-loss $(\mathrm{m})$ & Velocity $(\mathrm{m} / \mathrm{s})$ \\
\hline Tank- J1 & 300 & 279.8 & 48.9 & 0.37 & 0.69 \\
J1-J2 & 300 & 643.9 & 48.9 & 0.85 & 0.69 \\
J1-J11 & 250 & 450.5 & 48.9 & 1.44 & 0.99 \\
J2-J17-J30 & 200 & 774.7 & 48.9 & 6.95 & 1.5 \\
J10-J12-J16 & 160 & 768.1 & 48.9 & 21.66 & 2.42 \\
J11-J10-J9 & 160 & 224.2 & 48.9 & 6.32 & 2.42 \\
J9-J15-J8 & 160 & 265.3 & 48.9 & 7.48 & 2.42 \\
J8-J7-J6 & 160 & 355 & 48.9 & 10.01 & 2.42 \\
J6-J2 & 160 & 277.8 & 48.9 & 7.84 & 2.42 \\
J2-J3 & 160 & 271.8 & 48.9 & 7.67 & 2.42 \\
J19-J20 & 160 & 259 & 48.9 & 7.3 & 2.42 \\
J19-J30 & 160 & 293.4 & 48.9 & 8.28 & 2.42 \\
J21-J22-J20 & 160 & 634.1 & 48.9 & 17.88 & 2.42 \\
J16-J14-J5 & 75 & 1353.6 & 48.9 & 1533.33 & 11 \\
J5-J4 & 75 & 332.7 & 48.9 & 376.88 & 11 \\
J4-J3 & 75 & 335.6 & 48.9 & 380.16 & 11 \\
J5-J6 & 75 & 240.1 & 48.9 & 271.87 & 11 \\
J9-J13 & 75 & 414.6 & 48.9 & 469.65 & 11 \\
J27-J28 & 75 & 639.9 & 48.9 & 724.86 & 11 \\
J21-J23 & 75 & 333.1 & 48.9 & 377.33 & 11 \\
J23-J24 & 75 & 175.7 & 48.9 & 199.03 & 11 \\
J24-J25-J26 & 75 & 345.7 & 48.9 & 391.7 & 11 \\
J19-J25 & 75 & 341.4 & 48.9 & 386.73 & 11 \\
J26-J27 & 75 & 411.4 & 49.9 & 466.02 & 11 \\
J28-J29 & 75 & 367.4 & 48.9 & 416.18 & 11 \\
\hline TOTAL & LENGTH & 10788.8 & & & \\
\hline
\end{tabular}

Table 2. Shows the details of pipes laid at Ihumwa water supply network in Dodoma region. Discharges head-lose and velocity of the pipes from table 2 is calculated using computer water software.

Table 3: Average Discharge and Head-loss (HL) for the pipe used

\begin{tabular}{ccccc}
\hline Diameter $(\mathrm{mm})$ & Pressure $\left(\mathrm{N} / \mathrm{m}^{2}\right)$ & Discharge $(\mathrm{Q})(\mathrm{l} / \mathrm{s})$ & Headloss $(\mathrm{HL})(\mathrm{m})$ & Elevation $(\mathrm{m})$ \\
\hline 300 & 12 & 49 & 3.22 & 0 \\
250 & 12 & 48.9 & 1.44 & 0 \\
200 & 10 & 47.4 & 6.95 & 0 \\
160 & 10 & 48.9 & 10.5 & 0 \\
75 & 10 & 48.9 & 499.4 & 0 \\
\hline
\end{tabular}


Modeling and Optimization of Clean Water Distribution Networks

Table 3. Shows the averages of pipe discharges, head-loss; elevation of pipes calculated from table 2.

Table 4: Cost of pipe used

\begin{tabular}{cccc}
\hline Diameter(mm) & length $(\mathrm{m})$ & Cost per unit length(TZS) & Total Cost(TZS) \\
\hline 300 & 924 & 78260 & 72312240 \\
250 & 451 & 52440 & 23650440 \\
200 & 751 & 44230 & 33349420 \\
160 & 3283 & 41190 & 13945310 \\
75 & 5380 & 12680 & 67089880 \\
\hline Total length & 10788 & Total Cost & 334347290 \\
\hline
\end{tabular}

Table 4. Shows the cost of pipe used in the network.

Table 5: Quantities of chemicals and electricity

\begin{tabular}{lcc}
\hline MONTH & CHEMICALS (Kg) & ELECTRICITY (KWh) \\
\hline January & 676390 & 4179.68 \\
February & 598725 & 3370.76 \\
March & 721710 & 4447.21 \\
April & 595075 & 3895.38 \\
May & 776845 & 4323.99 \\
June & 678925 & 3903.20 \\
July & 780265 & 5017.82 \\
August & 731695 & 4794.49 \\
September & 725530 & 4538.19 \\
October & 647515 & 4960.54 \\
November & 690345 & 4856.01 \\
December & 669420 & 4838.86 \\
\hline Total & 8292440 & 53126.04 \\
\hline Average & 691036.67 & 4427.17 \\
\hline
\end{tabular}

Table 5. Shows the quantity of chemicals utilized for water treatment and the quantity of electricity utilized annually. The Average Quantity of energy (AQE) is in kWh.

Table 6: Cost of energy, treatment and maintenances/ operation, personnel cost

\begin{tabular}{llllr}
\hline Month & Energy cost(TZS) & Treatment cost(TZS) & $\begin{array}{l}\text { Maintenance } \\
\text { cost(TZS) }\end{array}$ & $\begin{array}{r}\text { Personnel } \\
\text { cost(TZS) }\end{array}$ \\
\hline January & 1437812.58 & 550154.3 & 142815.66 & 2739500 \\
February & 1159542.47 & 482400.45 & 138948.17 & 3353560 \\
March & 1529840 & 482400.45 & 162890.08 & 2758905 \\
April & 1340012.36 & 592573 & 162861.16 & 2258900 \\
May & 1487451.4 & 770491.33 & 164424.94 & 3590680 \\
June & 1342699.26 & 770491.33 & 164795.29 & 930800
\end{tabular}


Lucas Edward, Mashaka James Mkandawile and Verdiana Grace Masanja

\begin{tabular}{lllll} 
July & 1726131.58 & 779536.98 & 167046.38 & 3442000 \\
August & 1649303.26 & 736698.3 & 157902.79 & 2852770 \\
September & 1561136.88 & 933843.9 & 170776.23 & 5234190 \\
October & 1706424.45 & 836497.95 & 171417.747 & 4538500 \\
November & 1324500 & 1670468.16 & 922190.85 & 172909.84 \\
December & 1664566.2 & 887812.35 & 169732.44 & 3426700 \\
\hline Total & 16765388.6 & 8745091.19 & 1946520.72 & 33024305 \\
\hline Average & 1397115.717 & 728757.6 & 162210 & 2752025.417 \\
\hline
\end{tabular}

Table 6. Shows the cost of energy, chemicals, maintenance and personnel cost together with their total and averages which are used to calculate cost coefficients for energy, chemicals, maintenance and personnel cost.

Table 7: Calculated cost coefficients

\begin{tabular}{ll}
\hline Maintenance cost coefficient $(\beta)$ & 27035 \\
Energy cost coefficient $\quad(\alpha)$ & 315.58 \\
Chemical cost coefficient $(\delta)$ & 1.05 \\
Personnel cost coefficient $(\mu)$ & 34400.3 \\
\hline
\end{tabular}

Table 7. Shows the Calculated water treatment cost coefficients.

\subsection{Resulting model}

Objective function.

Minimize

$$
\begin{aligned}
72312240 X_{1}+ & 23650440 X_{2}+33349420 X_{3}+13945310 X_{4} \\
& +67089880 X_{5}+27035 Y_{1}+315.58 Y_{2}+1.05 Y_{3} \\
& +34400.3 Y_{4}
\end{aligned}
$$

Subject to the constraints

$$
\begin{gathered}
3.22 X_{1}+1.44 X_{2}+6.95 X_{3}+10.95 X_{4}+499.4 X_{5} \leq 750 \\
3.22 X_{1}+1.44 X_{2}+6.95 X_{3}+10.95 X_{4}+499.4 X_{5} \geq 690 \\
0.69 X_{1}+0.993 X_{2}-1.56 X_{3}+2.44 X_{4}+11.1 X_{5} \geq 0.5 \\
0.69 X_{1}+0.993 X_{2}-1.56 X_{3}+2.44 X_{4}+11.1 X_{5} \leq 3 \\
27035 Y_{1} \geq 16210.06 \\
315.58 Y_{2} \geq 1397115.717 \\
1.05 Y_{3} \geq 728757.6 \\
34400.3 Y_{4} \geq 2752025.417 \\
Y_{1}, Y_{2}, Y_{3}, Y_{4} \geq 0 \\
X_{1}, X_{2}, X_{3}, X_{4}, X_{5}, \geq 0
\end{gathered}
$$


Modeling and Optimization of Clean Water Distribution Networks

\section{Discussion}

The resulting optimisation model produced an optimisation problem which was solved with the help of LINGO (linear, interactive, discrete optimizer) software. The model shows that the unknowns for pipes and water treatment give optimal cost for clean water distribution networks. The unknown for pipes give the optimal solution under controlled minimum and maximum Pressure and velocity of water in the pipes.

\subsection{Costs comparison}

From table 4.1 the cost of the pipes is reduced from TZS 334,347,290 to TZS $322,664,634.4$ which equals $1.5 \%$ of the total pipes cost, while the cost of treatment is reduced from TZS 5,040,138.734 to TZS 4,894,084.659 which equals $2.9 \%$ of the total treatment cost.

The total cost of distributing clean water is reduced from TZS 339,387,428.7 to TZS $327,558,700$ which equals $4.4 \%$ of the total cost of distributing clean water in the given network.

Table 8: Comparison of the optimal and original costs of the decision variables of the

\begin{tabular}{llll}
\hline & \multicolumn{3}{c}{ model } \\
& OPTIMAL & ORIGINAL COST & DIFFERENCE \\
& COST & & \\
\hline PIPE COST & 322664634.4 & 334347290 & 11682655.6 \\
TREATMENT COST & 4894084.659 & 5040138.734 & 146054.075 \\
\hline TOTAL COST & 327558700 & 339387428.7 & 11828709.68 \\
\hline
\end{tabular}

\subsection{Maximum and Minimum pressure and velocity for optimal cost.}

From the model the minimum and maximum pressure that gives the optimal solution are $690 \mathrm{~N} / \mathrm{m}^{2}$ and $750 \mathrm{~N} / \mathrm{m}^{2}$, respectively, while the minimum and maximum velocities are $0.5 \mathrm{~m} / \mathrm{s}$ and $3 \mathrm{~m} / \mathrm{s}$, respectively, as shown in Table 9 .

Table 9: Maximum and Minimum velocity pressure for optimal cost.

\begin{tabular}{ccc}
\hline & velocity $(\mathrm{m} / \mathrm{s})$ & pressure $\left(\mathrm{N} / \mathrm{m}^{2}\right)$ \\
\hline Maximum & 3 & 750 \\
Minimum & 0.5 & 690 \\
\hline
\end{tabular}

\section{Conclusion}

The model developed in this study was used to optimize the cost of the clean water distribution network. Hydraulic data from the Dodoma region under DUWASA (Dodoma Urban water supply, Sanitation Authority) and treatment cost data from other literature are used to test the capabilities of the developed model.

The developed optimization model is characterized by non-linearity in the first term and it is linear in the second term. The non-zero unit variable is multiplied in the first term and its associated constrains in order to make the model linear which can be solved as a linear programming problem to find the optimal cost of distributing clean water.

The model representation of the delivery system for clean water was solved using LINGO software by testing different maximum and minimum pressure and velocities that gives minimum cost of distributing clean water in a given system. The maximum and 
Lucas Edward, Mashaka James Mkandawile and Verdiana Grace Masanja

minimum pressure that gives an optimal cost for distributing clean water are $700 \mathrm{~N} / \mathrm{m}^{2}$ and $650 \mathrm{~N} / \mathrm{m}^{2}$, respectively, while the maximum and minimum velocity are $3 \mathrm{~m} / \mathrm{s}$ and $0.5 \mathrm{~m} / \mathrm{s}$, respectively.

Acknowledgement. The authors gratefully acknowledge the Nelson Mandela African Institution for Science and Technology, German Academic Exchange Services (DAAD) for their financial assistance. As well, the authors thank to the reviewers for their valuable inputs.

\section{REFERENCES}

1. A.Boretti and L.Rosa, Reassessing the projections of the world water development report., NPJ Clean Water, 2, 15 (2019).

2. D.Mhiribidi, J.Nobert, W.Gumindoga and D.T.Rwasoka, Optimal water resource allocation modelling in the Lowveld of Zimbabwe, Proc. Int. Assoc. Hydrol. Sci., 378 (2018) 67.

3. M.Collins, L.Cooper, R.Helgason, J.Kennington and L.LeBlanc, Solving the pipe network analysis problem using optimization techniques, Manage. Sci., 24(7) (1978) 747-760.

4. J.A.Caballero and M.A.S.S.Ravagnani, Water distribution networks optimization considering unknown flow directions and pipe diameters, Comput. Chem. Eng., 127 (2019) 41-48.

5. M.J.Kadenge, V.G.Masanja, M.J.Mkandawile, Optimisation of water loss management strategies: multi-criteria decision analysis approaches, J. Math. Informatics, 18 (2020) 105-119.

6. A.Martin-Candilejo, D.Santillán, A.Iglesias and L.Garrote, Optimization of the design of water distribution systems for variable pumping flow rates, Water, 12(2) (2020) 359.

7. V.Marchionni, M.Cabral, C.Amado, and D.Covas, Water supply infrastructure cost modelling, Procedia Eng., 119 (2015) 168-173.

8. G.Cassiolato, E.P.Carvalho, J.A.Caballero and M.A.S.S. Ravagnani, Optimization of water distribution networks using a deterministic approach, Eng. Optim., 53(1) (2020) 107-124.

9. M.Maiolo, G.Mendicino, D.Pantusa, and A.Senatore, Optimization of drinking water distribution systems in relation to the effects of climate change, Water, 9(10) (2017) 803.

10. S.Bao-Feng and M.-Y.Du Xue, Optimization of tree pipe networks layout and size, using particle swarm optimization, WSEAS Trans. Comput., 13 (2014) 219-230.

11. J.Veintimilla-Reyes et al., MILP for optimizing water allocation and reservoir location: a case study for the machángara river basin, ecuador, Water, 11(5) (2019) 1011.

12. H.M.V.Samani and A.Zanganeh, Optimisation of water networks using linear programming, in Proceedings of the Institution of Civil Engineers-Water Management, 163(9) (2010) 475-485.

13. D.K.Boah, S.B.Twum and K.B.Pelig-Ba, Sensitivity and duality analysis of an otimal water treatment cost model for Ghana, International Journal of Mathematics and Statistics Studies, 4(2) (2016) 11-19. 